\title{
Development of Ganglion Cell Topography in Ferret Retina
}

\author{
Z. Henderson, ${ }^{1, a}$ B. L. Finlay, and K. C. Wikler \\ 1 University Laboratory of Physiology, Oxford University, Oxford OX1 3PT, UK, and Department of Psychology, Cornell \\ University, Ithaca, New York 14853
}

The adult ferret has approximately 90,000 retinal ganglion cells, arranged in a prominent area centralis and visual streak. The role of differential cell generation, cell death, and retinal growth in the control of adult retinal ganglion cell number and distribution was evaluated by examining basic aspects of retinogenesis, including growth in retinal area, developmental changes in the number, size, and distribution of retinal ganglion cells (identification aided by retrograde transport of HRP), and the incidence of degenerating cells in the ganglion cell layer. Retinal development in the ferret was also compared to retinal development in the cat (which has an even more differentiated area centralis) to determine what alterations of developmental parameters are most closely associated with this species difference in adult morphology.

The area of the retina increases linearly from birth (12 $\mathrm{mm}^{2}$ ) to postnatal day $24\left(54 \mathrm{~mm}^{2}\right)$, reaching an eventual adult value of $64 \mathrm{~mm}^{2}$. Ganglion cell numbers peak at 155,000 (approximately twice the adult number) on postnatal day 3 , and fall to adult numbers by postnatal day 6 . The remaining cells of the ganglion cell layer, principally displaced amacrine cells, reach their peak number on postnatal day $\mathbf{1 0}$ (approximately 280,000 ), falling to 200,000 by adulthood. Degenerating cells are abundant in the ganglion cell layer in the immediate postnatal period. A difference in the incidence of degenerating cells in the presumptive area centralis versus that in the retinal periphery was not observed postnatally, though there were other striking spatial nonuniformities, suggesting that differential cell loss might contribute to other features of retinal topographic organization.

Ganglion cell density is virtually uniform across the retina at birth. Cell density is first reduced in the dorsal retina, resulting in a dorsal-to-ventral gradient in cell density that persists until day 10 , when ganglion cell number has stabilized. By postnatal day 24 , an area centralis and visual streak has emerged, but not of adult magnitude. Because ganglion cell number has stabilized long before the area centralis and visual streak emerge, we conclude that differential retinal growth is the principal mechanism producing

Received Apr. 25, 1986; revised July 20, 1987; accepted Sept. 14, 1987

This work was supported by UK Medical Research Council Grant G979/49 to Z.H., and NIH Grants K01 NS00783 and R01 19245 to B.L.F. We are indebted to Colin Blakemore (holder of the MRC program Grant G979/49) for encouragement and support throughout this study. We also thank the Guarantors of Brain and the Morgan E. Williams Bequest Fund (Welsh National School of Medicine) for providing travel grants for Z.H.

Correspondence should be addressed to B. L. Finlay, Department of Psychology, Uris Hall, Cornell University, Ithaca, NY 14853.

a Present address: Department of Physiology, The Worsley Medical and Dental Building, The University, Leeds LS2 9NQ, UK.

Copyright (C) 1988 Society for Neuroscience $0270-6474 / 88 / 041194-12 \$ 02.00 / 0$ this feature of retinal topography. Comparison with the cat suggests that the proportionately greater nonuniform growth of the cat's eye accounts for the greater differentiation of its area centralis.

Mammalian eyes differ markedly in their absolute size, and in number of retinal ganglion cells. They also differ in the topography of the distribution of these cells across the retinal surface, including relatively flat distributions, horizontally elongate "visual streaks" of high cell density, L-shaped distributions with cell density elevated on the horizontal and part of the vertical meridian, and area centralis (Hughes, 1977; Stone, 1983). Finally, they differ in the relative extent to which each of these features is elaborated in various mammalian radiations (for example, marsupials, rodents, ungulates, and carnivores all have individual species in which either the visual streak or area centralis is either well developed or underdeveloped).

Since the list of candidate devclopmental mcchanisms that could produce increased cell concentration in any retinal area (or in any neural surface) is not long, a comparative analysis of the development of retinal topography is a profitable way to begin to describe the paths by which vertebrate nervous systems have differentiated and evolved. To produce regional differences in cell density, cells could be locally generated in higher numbers to produce high-density areas. Alternatively, after generation, cells could die in excess or redifferentiate as other cell types to produce low-density areas of a particular cell class, or cells could migrate from low- to high-density areas. Finally, differential stretch or expansion of a uniformly dense surface could result in low- and high-density areas (Stone et al., 1982). The diversity in the mechanisms by which retinal topographies are produced in separate radiations is of interest in determining whether there are constraints on mechanisms by which vertebrate eyes may evolve.

Nonuniform cell generation, cell death, and retinal growth have each been shown to contribute to the development of topographic specializations in the retina (redifferentiation of cell classes and large transretinal migrations of cells have not been directly demonstrated). The directions and the relative and $a b-$ solute magnitudes of the contribution of each mechanism vary between species. During development, cell generation can give rise to retinas that initially have 1.5-4 times (depending upon species) the adult number of ganglion cells or optic nerve axons (rat: Lam et al., 1982; Potts et al., 1982; Perry et al., 1983; Crespo et al., 1985; hamster: Sengelaub and Finlay, 1982; Sengelaub et al., 1986; cat: $\mathrm{Ng}$ and Stone, 1982; Stone et al., 1982; Williams et al., 1986; monkey: Rakic and Riley, 1983; human: Provis et al., 1985a, b). During the period of development when retinal ganglion cell numbers are at a maximum, cell density 
may be highest in the retinal periphery (hamster: Sengelaub et al., 1986), uniform across the retina (rat: Perry et al., 1983; cat: Stone et al., 1982), or somewhat elevated centrally (rabbit: Stone et al., 1985; human: Provis et al., 1985a). The extent to which differential cell death is involved in the transformation of the adult retinal ganglion cell distribution from the immature to the adult formation varies in the few species described. It contributes substantially to retinal topography in the human (Provis, 1987) and the hamster (Sengelaub et al., 1986), but is not observed in rabbit (Robinson, 1987) or rat (Horsburgh and Sefton, 1985), and its role is debated in the cat (Stone and Rapaport, 1986; Lia et al., 1987; Wong and Hughes, 1987c). In every retina in which this has been examined, differential retinal growth or stretch contributes to cell topography, but in different amounts (Mastronade et al., 1984; Robinson et al., 1986; Sengelaub et al., 1986; Robinson, 1987), and the significance of this variability is unknown. Systematization of the variability in developmental mechanisms across animals will require assembly of information about adult eye topography and its degree of differentiation, rate and duration of development, and the evolutionary relationship of the animals studied. The study of additional animals, chosen to provide new and appropriate contrasts, is also necessary.

The ferret is an animal both convenient for exploration of the mechanisms involved in creation of retinal topographies and interesting for several comparative contrasts, particularly with the relatively closely related cat. In particular, it allows investigation of the effect of eye size (and thus retinal growth) on the development of an area centralis, holding other features relatively constant. The time from conception to eye opening is roughly comparable in ferrets (72 d) and the cat (75 d), though birth is earlier in the ferret, at $42 \mathrm{~d}$ of gestation compared to 63 $\mathrm{d}$ in the cat (Greiner and Weidman, 1981; Linden et al., 1981). Retinal ganglion cell number in the ferret, which is 90,000 (Henderson, 1985) is substantially less, however, than the 150,000 figure for the cat (Illing and Wässle, 1981; Chalupa et al., 1984). The contrast in cell density from area centralis to periphery is about 10-12/1 in the ferret (Henderson, 1985), and well in excess of $30 / 1$ in the cat (Stone, 1965, 1978; Hughes, 1975). Ferrets are comparable in eye size and retinal ganglion cell number to several well-studied rodents (rat, gerbil, and hamster), but have a much more developed area centralis, and a longer time from conception to eye opening.

In this study we describe the transformation of the number and topography of the cell classes in the retinal ganglion cell layer from birth to adulthood in the ferret. We then discuss the minimal and maximal contributions of cell generation, cell death, and retinal growth to the determination of adult cell topography to the extent that they may be dissociated using the techniques employed, and compare the pattern observed in the ferret to that observed in closely and distantly related species. A preliminary report of this investigation has been made by Henderson et al. (1985).

\section{Materials and Methods}

All experiments were done on animals with heavily pigmentcd cpithclium behind the retina, and bred in the laboratory from timed pregnancies. From postnatal (P) day 1 (the day of birth) to adulthood, the spatial distributions of retinal ganglion cells, nonretinal ganglion cells, and degenerating cells were reconstructed from paraffin-embedded, horizontally sectioned eyes stained with cresyl violet. Out of a total of 34 animals, 17 eyes, one from each animal, were analyzed in full at P1 $(n=2), \mathrm{P} 2(n=2), \mathrm{P} 3(n=3), \mathrm{P} 6(n=3), \mathrm{P} 10(n=3), \mathrm{P} 24(n=2)$,

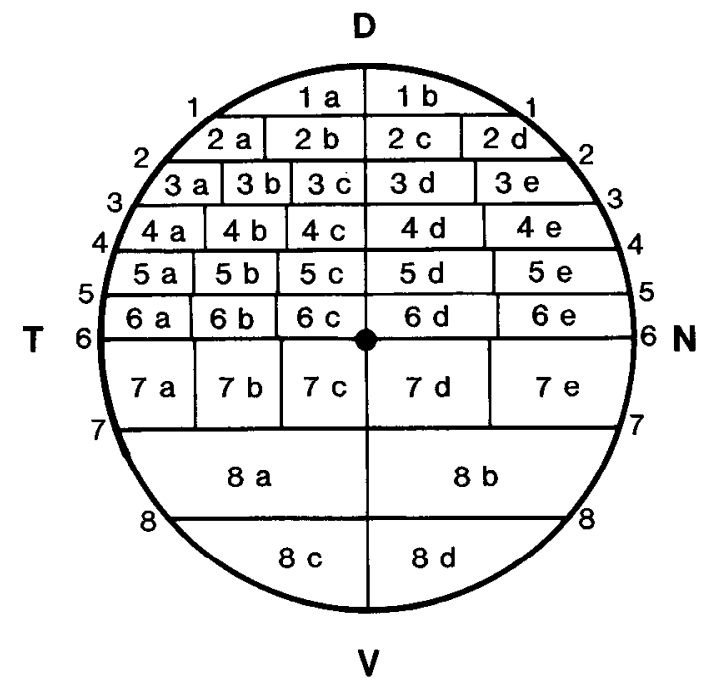

Figure 1. Schematic diagram of the horizontal level of each retinal section $(1-8)$ and divisions of each retinal section $(a-e)$ used for all the retinas described in this study. Cell numbers for the density calculations for each area of retina were determined from the immediately subjacent retinal division, as indicated.

and at adulthood $(n=2)$. For every postnatal day but P1 and P24, retinal ganglion cell identification was aided by retrograde labeling with HRP after multiple injections of the enzyme into the thalamus and superior colliculus (11 animals). The retinas were analyzed and reconstructed from horizontal sections rather than from wholemounts. In wholemounts, the thickness of the retinal ganglion cell layer and the lack of differentiation of the inner plexiform layer in neonates make accurate resolution of the ganglion cell layer quite difficult. In addition, the problem of differential shrinkage of wholemounts at the edges, a central concern for questions of development of cell distribution, can be avoided entirely.

Nissl-staining procedures. Animals that did not receive injections of HRP into the brain were given a lethal dose of sodium pentobarbital and perfused through the ascending aorta with Formol saline. A suture was placed in the conjunctivum of the eye at the superior margin of the cornea, and, after dehydration of the eye in alcohols, the cornea was removed and the rest of the eye embedded in paraffin wax. For the smallest animals $(P 1-3)$, the entire head was embedded in paraffin. Serial $10 \mu \mathrm{m}$ sections were cut horizontally, beginning from the suture, and were mounted on slides and stained for Nissl substance with cresyl violet.

HRP procedures. Eleven animals had HRP injected bilaterally into the diencephalon and midbrain at P1, P2, P5, and P9, and at adulthood. One of the animals, an adult, was injected bilaterally with HRP, as described by IIenderson (1985). Animals at P1, P2, and P5 were anesthetized using hypothermia, and those at P9 with halothane $(1 \%$ in oxygen). For each of these immature animals 8 injections of a total of $0.8 \mu \mathrm{l}$ of $30 \%$ HRP were distributed bilaterally into the thalamus and superior colliculus by pressure injection through the $30 \mu \mathrm{m}$ tip of a glass micropipette. After full recovery, the animals were returned to the litter. The next day they were given a lethal dose of sodium pentobarbital and perfused via the ascending aorta with fixative containing $1-2.5 \%$ glutaraldehyde and $1 \%$ paraformaldehyde in $0.1 \mathrm{~m}$ phosphate buffer. In order to prevent the retinas in the immature animals from becoming hard and brittle, the lengths of the perfusions were restricted to $10 \mathrm{~min}$. The brains, which appeared to be underfixed by this procedure, were removed and put into the same fixative for $24 \mathrm{hr}$, and were then sunk in $30 \%$ sucrose. Sections of the brain were cut at $50 \mu \mathrm{m}$ and stained for HRP (see below) to verify the spread of the marker throughout the midbrain and diencephalon.

Immediately after perfusion, the eyes were removed and reacted for HRP activity with a diaminobenzidine-cobalt procedure. Diaminobenzidine histochemistry, although less sensitive than that using tetramethylbenzidine as a chromogen, is fully compatible with the paraffin-embedding and cresyl violet-staining procedures required for the optimal visualization of normal and degenerating cells in the developing 

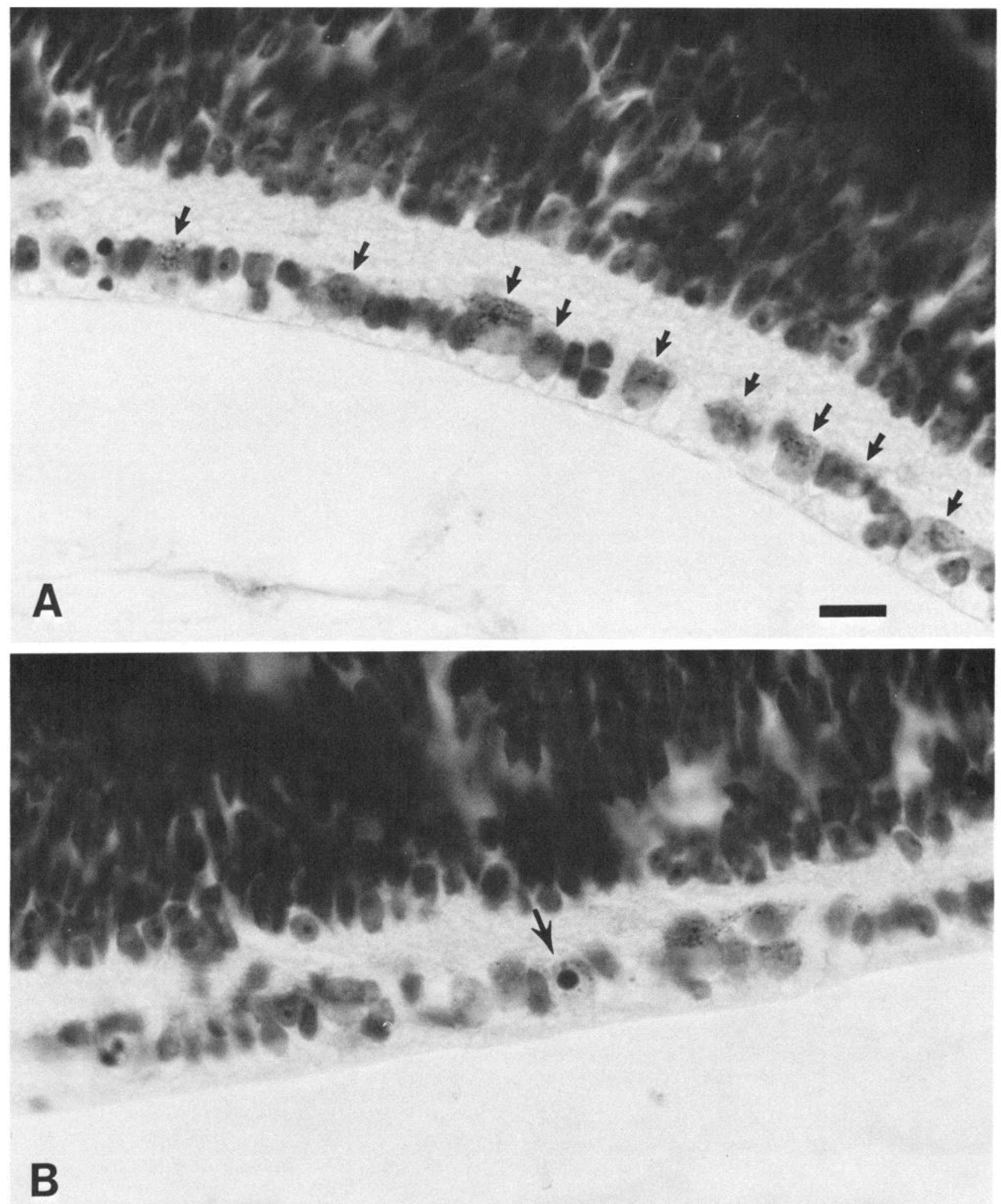

Figure 2. Photomicrographs of cells in the ganglion cell layer at P6. A, Retinal ganglion cells (arrows) have been labeled by retrograde transport of HRP and have a morphology quite distinct from the remainder of the nonlabeled cell population (probably composed of glia and displaced amacrine cells). $B$, A pyknotic cell labeled with HRP (arrows), indicating that it is a dying retinal ganglion cell. Calibration bar, $10 \mu \mathrm{m}$.

retina. A suture was placed in the superior part of the eye and all adhering muscle and tissue cleared away; the cornea and lens and part of the vitreous were removed. The eye was washed several times in phosphate buffer and reacted for HRP for 30 min using Adams' cobalt-diami- nobenzidine method (Adams, 1977). The eyes were embedded in paraffin, sectioned, and counterstained for Nissl substance using cresyl violet, as described above.

Analysis of sections. For each eye, serial horizontal sections from the 
uppermost margin of the retina to the lowest were available for study. From these, 8 sections were selected for detailed analysis, their spacing chosen to give greater resolution to the presumptive area centralis and visual streak regions (as determined from the adult flat-mounted retinas (Henderson, 1985). These included 5 equally spaced sections (1-5) lying between the dorsal margin of the retina and the center of the optic disc, one section (6) through the center of the optic disc, and 2 sections (7 and 8) equally spaced between the center of the optic disc and the ventral margin of the retina (Fig. 1). Except for the last section, each section was treated as a sample of the strip of retina just above it, and was subdivided into 2-5 pieces (Fig. 1). This pattern and frequency of sampling gave ratios of center/periphery cell densities in adults similar to those determined from wholemounts, and was approximately a $5 \%$ sample, similar to that used in wholemounts.

The locations of ganglion cells, as assisted by HRP identification, other cells, and pyknotic degenerating cells, were plotted directly at $750 \times$ with a computer-aided camera lucida and graphics tablet system. Cell counts for each section were determined and then corrected for the relationship of frequency of encounter to cell size and section thickness (Abercrombie, 1946) and for section obliquity (progressive deviations from normality in section angle are associated with progressively greater apparent retinal thickness; see Appendix for the derivation of this formula). The cell density in each piece of retina after these corrections was displayed as the number of cells $/ \mathrm{mm}^{2}$. Owing to the change in retinal size and the fact that cell distributions were often flat or concave, isodensity lines constructed in the traditional manner were not informative. The counts were grouped in coded "bins" that increased in width on a logarithmic scale of $\log _{2}$, i.e., the range of cell densities of cells in each successive "bin" being twice that of the previous bin (Figs. $5,6)$.

For each age, cell diameters from representative retinas were measured by sampling from 4 to 5 different section levels. The outlines of the cells were drawn with a camera lucida and averages taken of the minimum and maximum diameters of cell bodies.

The area of the retina, the proportion of the eye occupied by the retina, and the total number of retinal ganglion cells for each eye were computed using solid geometry to determine the area of the strip of retinal surface above each section analyzed (see Appendix for the derivation of retinal area formulas).

For comparison over development, the retina was always subdivided into the same angular proportions. Since the retina grows during this period, the absolute size of each subdivision increases. Since the retina is also unlikely to grow uniformly during this period (Mastronade et al., 1984), no presumption is made here that equivalent angular subdivisions of the retina capture the identical physical parts of the retina at different ages.

\section{Results}

\section{Identification of cell types}

From $\mathrm{P} 2$ to $\mathrm{P} 10$, the retinal cells that became retrogradely labeled with HRP after injection of the marker into the visual centers of the brain were invariably large, pale-staining cells (Figs. 2, 3), $8 \pm 1 \mu \mathrm{m}$ in diameter ( $\pm \mathrm{SD}$ ). These cells had a large, round nucleus and a thin rim of cytoplasm concentrated above the apex of the nucleus (Fig. 2A). The cells that did not take up the HRP label on any occasion were darkly staining cells, $6 \pm 1 \mu \mathrm{m}$ in diameter, with a dark oval nucleus, a prominent nucleolus, and barely visible cytoplasm (Figs. 2, 3). In the ventral retina of some newborn animals, the dark cells formed a separate layer between the ganglion cells and the inner plexiform layer; in other parts of the retina they formed clusters within the retinal ganglion cell layer itself.

On the basis of the results from the HRP studies, the identification of retinal ganglion cells in all the P2-P10 retinas was made according to morphological criteria. By P24, the retinal ganglion cells had acquired substantial amounts of Nissl substance in their cytoplasm, making it easier to identify them in Nissl-stained retinas, and they showed obvious differentiation into alpha, beta, and gamma subtypes (Henderson, 1985; Vitek et al., 1985). By adulthood, the average size of the ganglion cells

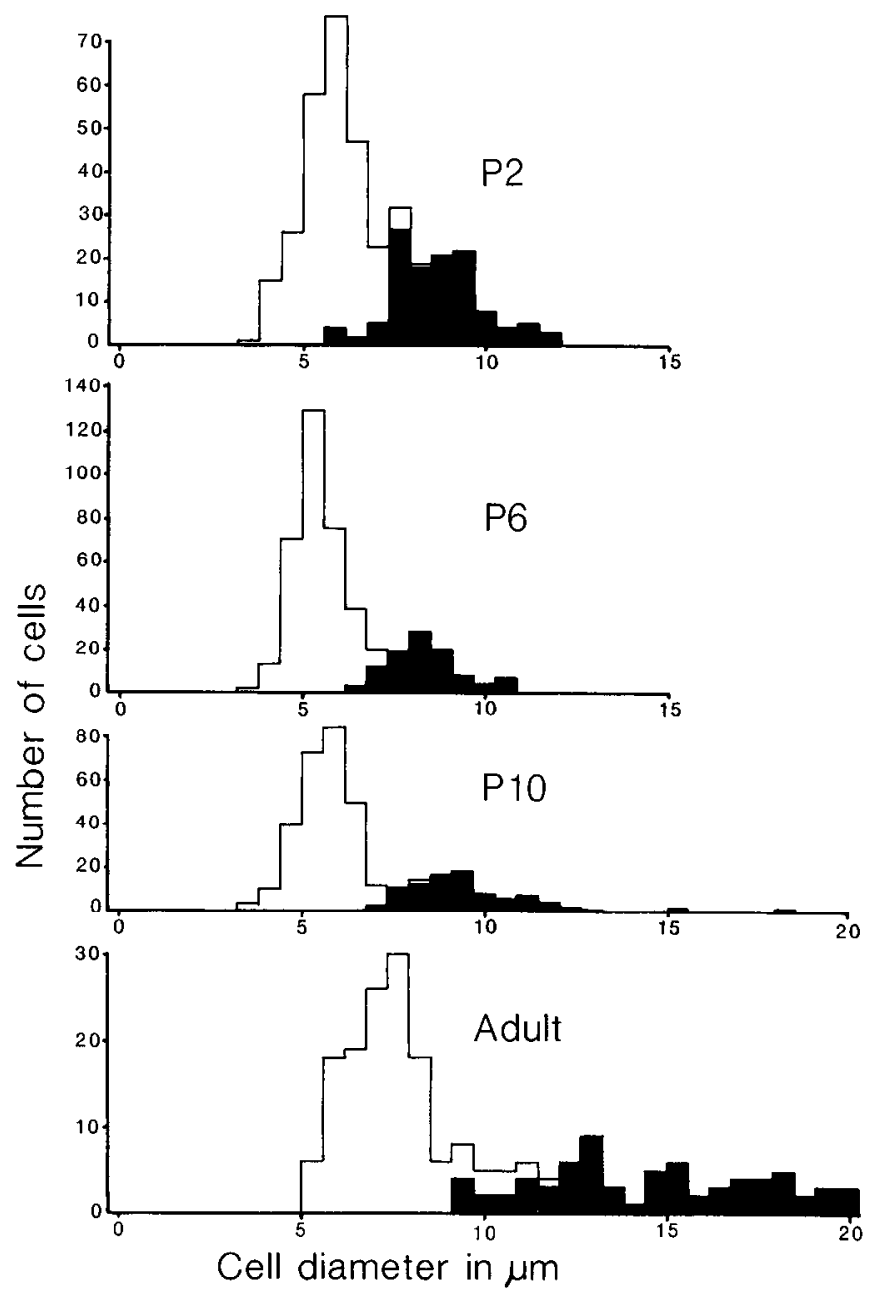

Figure 3. Frequency distributions of soma size in ferret retinal ganglion cell layer at different ages. The filled parts of the bins represent cells retrogradely labeled with HRP after bilateral injections of the marker into the visual centers of the brain.

was $14 \pm 3 \mu \mathrm{m}$ (Fig. 3), the approximate doubling in size from birth to adulthood being due entirely to the increase in the volume and contents of the cytoplasm, rather than to growth of the nucleus. The sizes of the cells classified as nonretinal ganglion cells remained at an average of $7 \pm 1 \mu \mathrm{m}$, consistent with their lack of development of Nissl substance (Fig. 3). Mitotic figures were commonly observed from P6 onwards in the ganglion cell layer and were presumably a manifestation of in situ gliogenesis.

Dying cells in the retinal ganglion cell layer were identified as pyknotic cells undergoing a "nuclear"-type degeneration (Cunningham et al., 1982): these cells contained one or more droplet-like granules (1-3 $\mu \mathrm{m})$ of dense chromatin occasionally bounded by nuclear membrane and pale cytoplasm (Fig. $2 B$ ). In the HRP-injected animals, a proportion of the pyknotic cells possessed granules of HRP label in the cytoplasm (Fig. 2B), confirming that some pyknotic cells are indeed ganglion cells. We examined the distribution of pyknotic cells expressed both as an incidence of all cells or of ganglion cells only, and also their absolute incidence. No method produced significant uniformities in cell degeneration related to the adult center/periphery disparity. Represented in Figure 4 is the incidence of degenerating cells, averaged over $2-3$ retinas for each age, and 

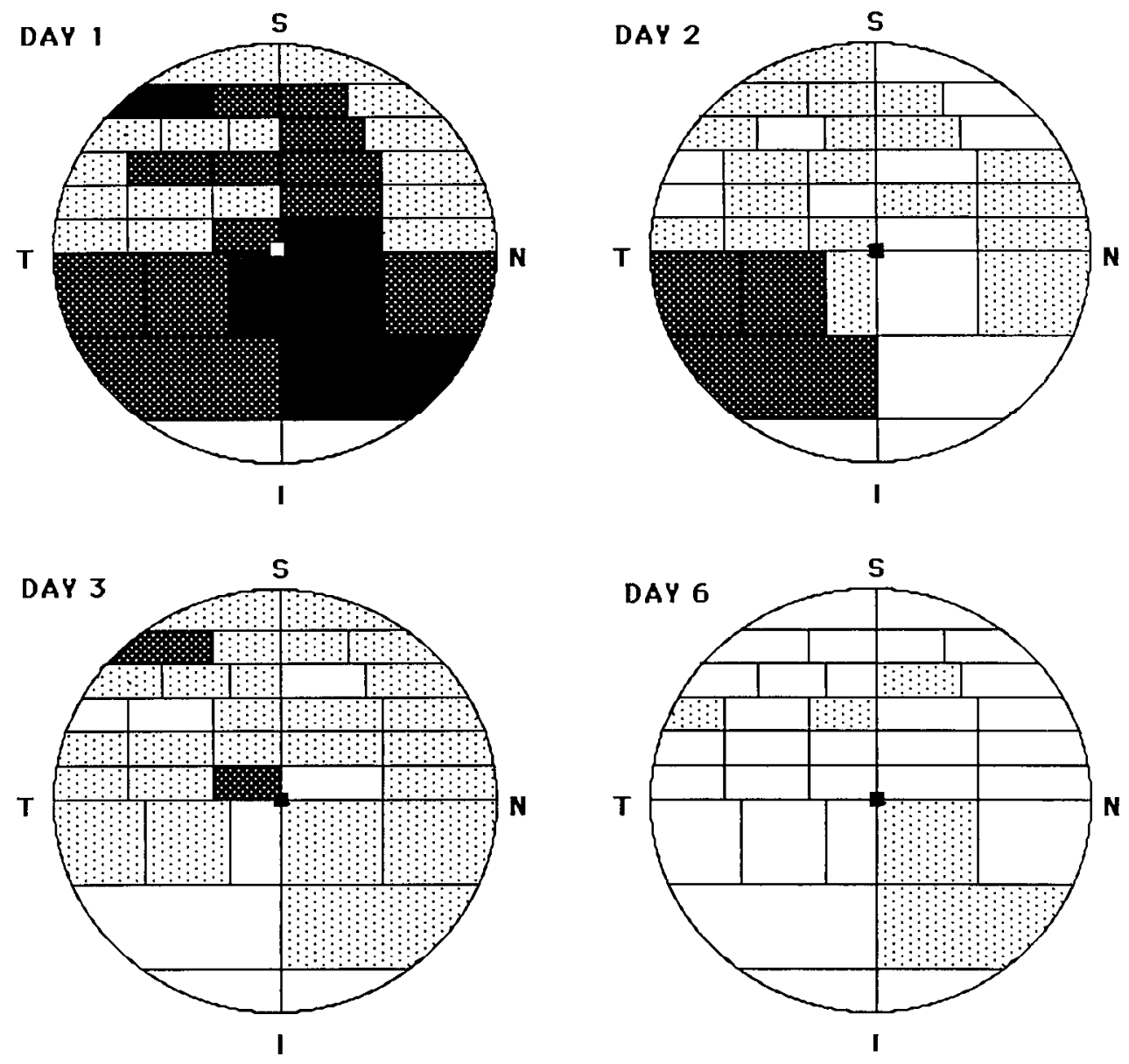

Figure 4. Distribution of relative incidence of pyknotic cells in the retinal ganglion cell layer at different ages.

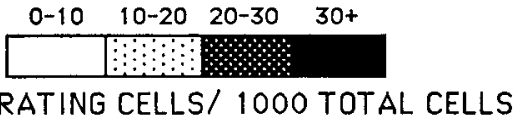

expressed as a fraction of all cells. This is the most conservative method, since we did not know if every degenerating cell in early development was a ganglion cell. We did not express cell death as an absolute incidence (cells $/ \mathrm{mm}^{2}$ ) because overall cell density did not remain constant over the time period we examined.

\section{Distribution of ganglion cells}

The distribution of ganglion cells found in the retinas of ferrets of different ages is shown in Figure 5. The density of cells was practically uniform across the retina at $\mathrm{P} 2$, but by $\mathrm{P} 3$ a shift had occurred in the distribution of ganglion cells, so that their density increased gradually in the dorsal-to-ventral direction. At $\mathrm{P} 6$ the dorsal-to-ventral gradient in cell density persisted, but the overall density had fallen and the number of cells $/ \mathrm{mm}^{2}$ in the high-density region of the P6 retina was of the same order as that of the arca centralis/visual streak region in the adult retina. By $\mathrm{P} 24$, the retinal ganglion cells were organized into a visual streak/area centralis, although the full center/periphery disparity in cell density of the adult was not reached. There was a flat distribution of cells in the periphery at a density of between 1600 and 3300 cells $/ \mathrm{mm}^{2}$ (Fig. 5). The retinal ganglion cell distribution in aduits was very much as described previously in wholemounts of adult retinas (Henderson, 1985). The ganglion cells were not symmetrically distributed about the horizontal axis through the optic disc; in the dorsal half of the retina most of the ganglion cells were concentrated in the area centralis and visual streak and their numbers fell off rapidly towards the periphery to under 400 cells $/ \mathrm{mm}^{2}$; in the ventral half of the retina the ganglion cells were more uniformly distributed and were of an intermediate density, between 400 and 800 cells/ $\mathrm{mm}^{2}$.

The overall density of nonganglion cells fell from $\mathrm{P} 10$ onwards (Fig. 6), and the change in ganglion cell density into a streak was accompanied by a decline in the density of nonganglion cell types in the visual streak/area centralis region.

\section{Ganglion cell numbers and retinal areas}

The changes in the number of retinal ganglion cells with age are shown in Figure 7. The number of ganglion cells rose from an average of 110,000 at $\mathrm{P} 2$ to 150,000 at $\mathrm{P} 3$, peaked somewhere between P3 and P6 (range, 140,000-158,000), and fell to the adult figure of $80,000-90,000$ cells by P6, after which their numbers remained relatively stable. The average numbers of cells directly identified as ganglion cells by the HRP method was $93,400 \pm 8100$ from P6 onwards, consistent with the figure of 80,000-90,000 obtained for adults with other techniques (HRP wholemounts: Henderson, 1985, and optic axon counts, unpublished results).

The combined numbers of ganglion and nonganglion cells rose 
P2

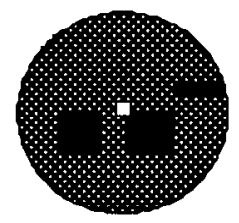

P3

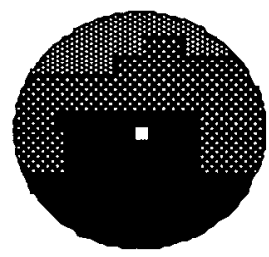

P6
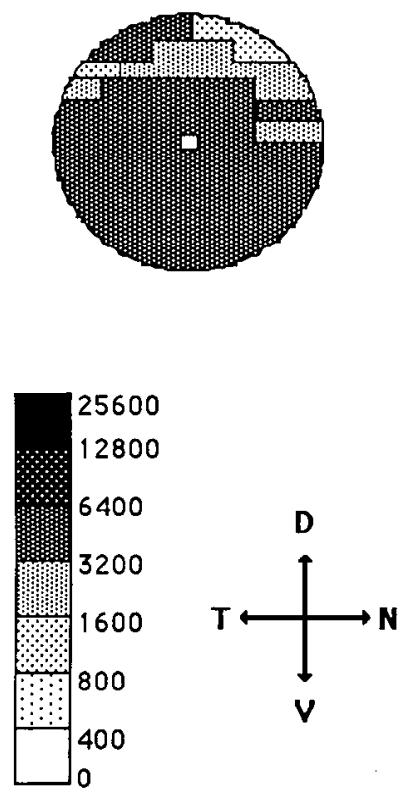

P10
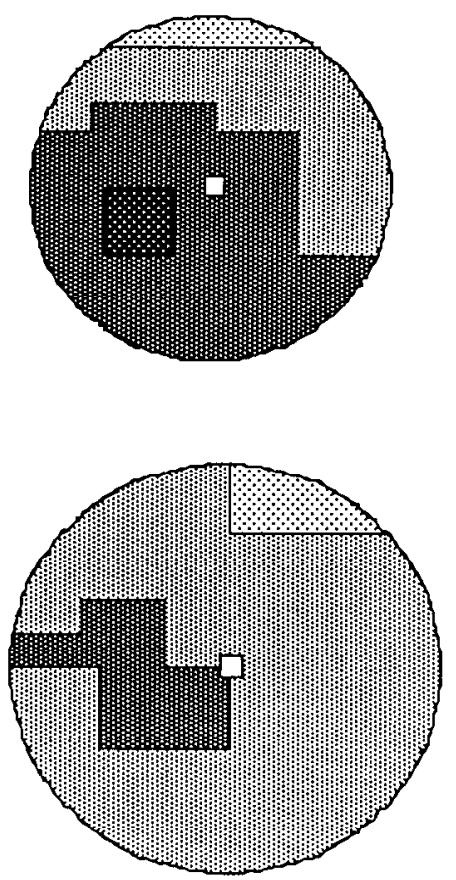

P24

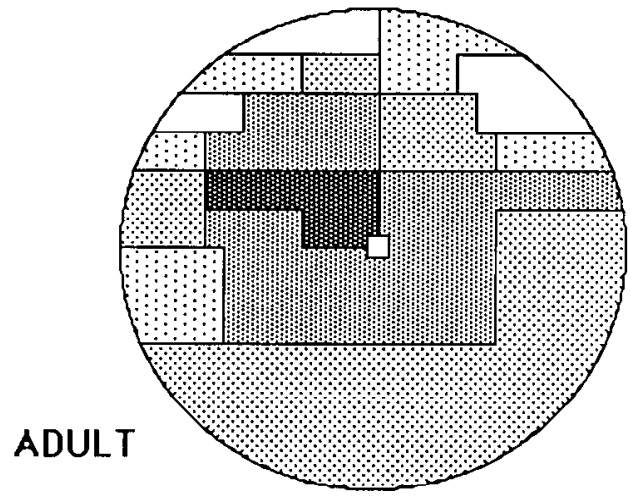

\section{CELLS/ MM 2}

Figure 5. Density distribution of retinal ganglion cells in ferret retina from P2 to adult. The retinas are drawn in proportion to their flat areas. The circle in the center is the optic nerve. sharply from 200,000 cells immediately postnatally to 350,000 cells by $\mathbf{P} 10$, and then the numbers gradually dropped, reaching 275,000 by adulthood. The proportion of the cells that were ganglion cells also varied with age: the ganglion cells were half of all the cells at P1-3, a quarter at P6, and a third in the adult.

The area of the retina grew at a steady rate from birth to P24 (Fig. 8); it was at an average of $12 \mathrm{~mm}^{2}$ at birth, $12 \mathrm{~mm}^{2}$ at P2, $17 \mathrm{~mm}^{2}$ at P3, $20 \mathrm{~mm}^{2}$ at P6, $27 \mathrm{~mm}^{2}$ at P10, and $54 \mathrm{~mm}^{2}$ at P24; the retinal area at P24 was still smaller than the $64 \mathrm{~mm}^{2}$ of the adult. By adulthood the area of the retina is 6-7 times larger than it is at birth. No correction was made for shrinkage, and thesc values for retinal area should be considered relative to each other rather than as absolute figures.

\section{Cell death}

The incidence of cell death in the retinal ganglion cell layer is indicated by the numbers of dying cells per 1000 normal cells, displayed for different ages in Figure 6 . Average cell death was highest at birth $(20 \pm 8 / 1000)$, dropped slowly towards P6 and rose again at P10; it was (per thousand) $13 \pm 6$ at P2, $12 \pm 5$ at $\mathrm{P} 3,7 \pm 3$ at $\mathrm{P} 6$, and $13 \pm 4$ at $\mathrm{P} 10$. Cell death in the retinal ganglion cell layer was virtually nil at P24. No significant difference ( $p>0.05 ; 2$-tailed $l$ test) in average cell death incidence was observed between the prospective area centralis/visual streak region and the retinal periphery at any age (Fig. 9). Also, there was no significant difference between cell death rates in the dorsal and ventral halves of the retina, except at $\mathrm{P} 2$, in which the cell death rate was significantly greater in the ventral half of the retina than in the dorsal half $(p<0.01)$, shown in Figure 9. Throughout the developmental period from P1 to P24, pyknotic cells were abundant in the inner nuclear layer of the retina, including the amacrine cell stratum, increasing the likelihood that pyknosis in the ganglion cell layer involved both ganglion and nonganglion cells.

\section{Discussion}

In this study on the development of the retina of the postnatal pigmented ferret, we have described changes with age in the area of the retina, the distribution and numbers of ganglion cells, and the incidence of degenerating cells in the retinal ganglion 
P2

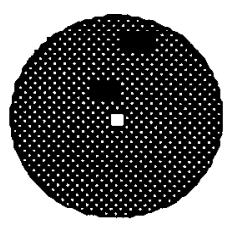

P3

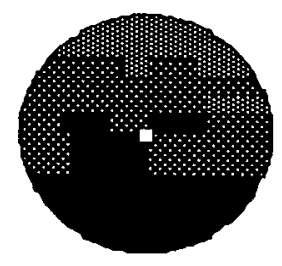

P6

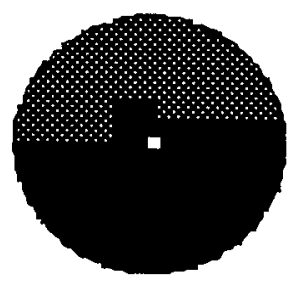

CELLS/MM ${ }^{2}$

Figure 6. Density distribution of nonretinal ganglion cells.

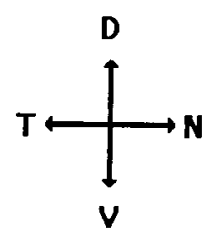

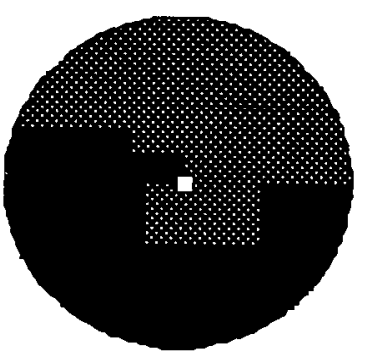

P10
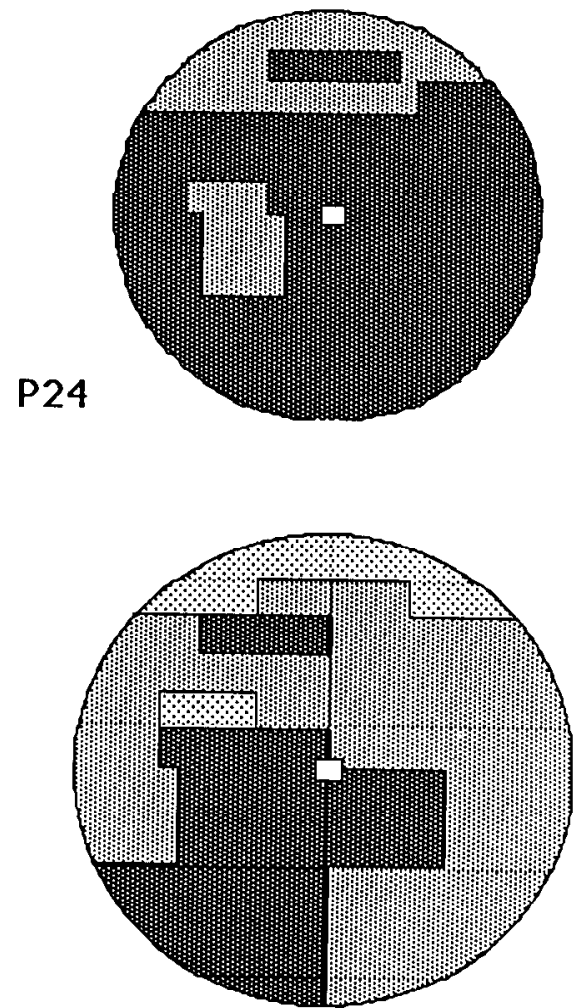

ADULT cell layer. The significance of these observations is discussed in the following sections.

\section{Identification of cell types in the retinal ganglion cell layer}

To establish the identity of the retinal ganglion cells with greater certainty, we combined Nissl staining with retrograde transport of HRP. In most other studies of retinal development, the identification of retinal ganglion cells has been performed using Nissl staining or retrograde labeling alone. Since our study was also based on the distribution and numbers of spontaneously degenerating cells in the retinal ganglion cell layer, we had to ensure that the injection of HRP for retrograde labeling caused as little damage as possible at the injection site. Therefore, we avoided the commonly used method of implanting HRP directly into the optic tract or optic nerve, and instead injected the HRP through the fine tip of a glass micropipette inserted in target areas in the brain. Only half the animals received the HRP injections, and no differences in cell death incidence were noted between the retinas from control and HRP-injected animals. In our retinal preparations, the intensity of retrograde labeling for HRP was admittedly variable across the retina, and since diaminobenzidine is a relatively insensitive chromogen, the labeling was not always clearly visible in portions of the retina. Therefore, retrograde labeling with HRP was not used as the sole criterion for the identification of retinal ganglion cells. Instead, the cells were distinguished by their characteristic morphology: in the areas of retina intensely stained for HRP, the HRP label was found only in the cells that were large and palestaining for Nissl, and not in the cells that were small and darkly staining (Fig. 2). This morphological classification for ganglion and nonganglion cells also corresponds to that employed in neonatal rat retina (Cunningham et al., 1982; Perry et al., 1983).

A potential confound with the use of retrograde transport of HRP during development to identify ganglion cells, however, is that immature retinal ganglion cells not yet possessing a central axon might also have the nuclear characteristics of being small and darkly staining, and thus be systematically misidentified. While this possibility cannot be ruled out entirely, we 


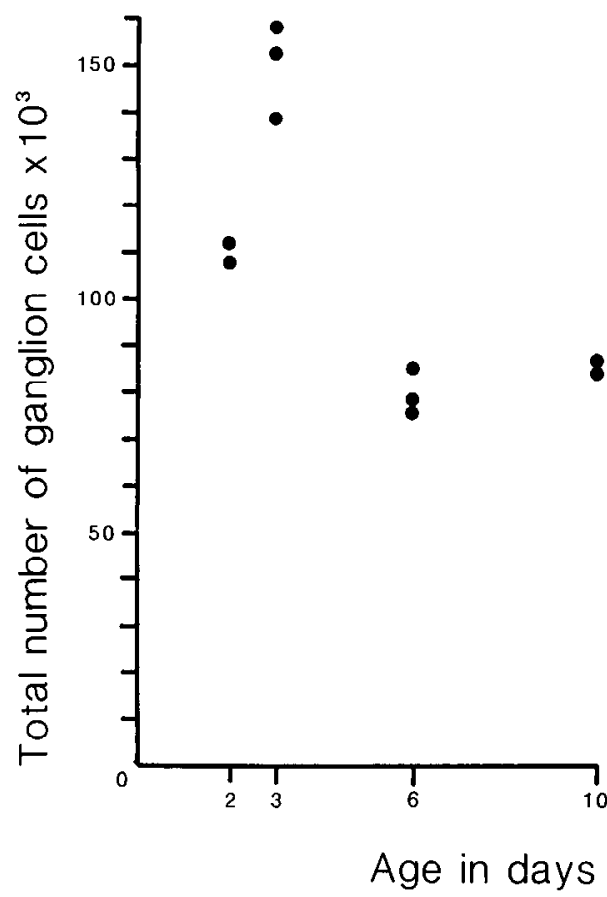

Figure 7. Changes in the total number of retinal ganglion cells with age. Circles represent figures obtained from this study, diamonds are adult counts obtained from wholemounts (Henderson, 1985), and triangles are fiber counts done on adult optic nerve (unpublished results).

view it as unlikely for the following reasons: (1) If maturation and ganglion cell identification are confounded, then ganglion and nonganglion cell densities should show indication of changing reciprocally in early development as ganglion cell identification is aided by maturation, but no such relationship was seen (Figs. 5, 6). Nuclear, as opposed to somal, diameter shows no indication of growth over development for either nuclear cell class. (2) In other species, Golgi studies (rat: Perry and Walker, 1980) and thymidine-labeling studies (hamster: Sengelaub et al., 1986; and unpublished observations) suggest that ganglion cells have characteristic and recognizable morphologies from their first appearance in the ganglion cell layer. In sum, these arguments do not constitute complete proof that retrograde HRP labeling can be used to unambiguously identify or infer that cells are of ganglion cell nuclear morphology at all states of maturation. However, in the absence of any direct evidence that cells change these features of nuclear morphology during development, we are reasonably confident that the early cell counts and density distribution accurately reflect actual retinal ganglion cell number.

In the neonate animals it is quite likely that the majority of the dark-staining cells in the ganglion cell layer were displaced amacrine cells; according to Perry et al. (1983), they form the majority of nonganglion cells in the neonate rat ganglion cell laycr. In the ferret, however, the presence of mitotic figures in the ganglion cell layer from P6 onwards suggests that a proportion of nonganglion cells from then on are also glia. In this study, therefore, we confined ourselves to approaching nonganglion cells as a single entity, since we found the Nissl-stained material to be inadequate for distinguishing displaced amacrine cells from glia. In the adult rat, as many displaced amacrine cells as ganglion cells are found in the ganglion cell layer (Perry, 1981), and it is suggested that displaced ganglion cells are prev-

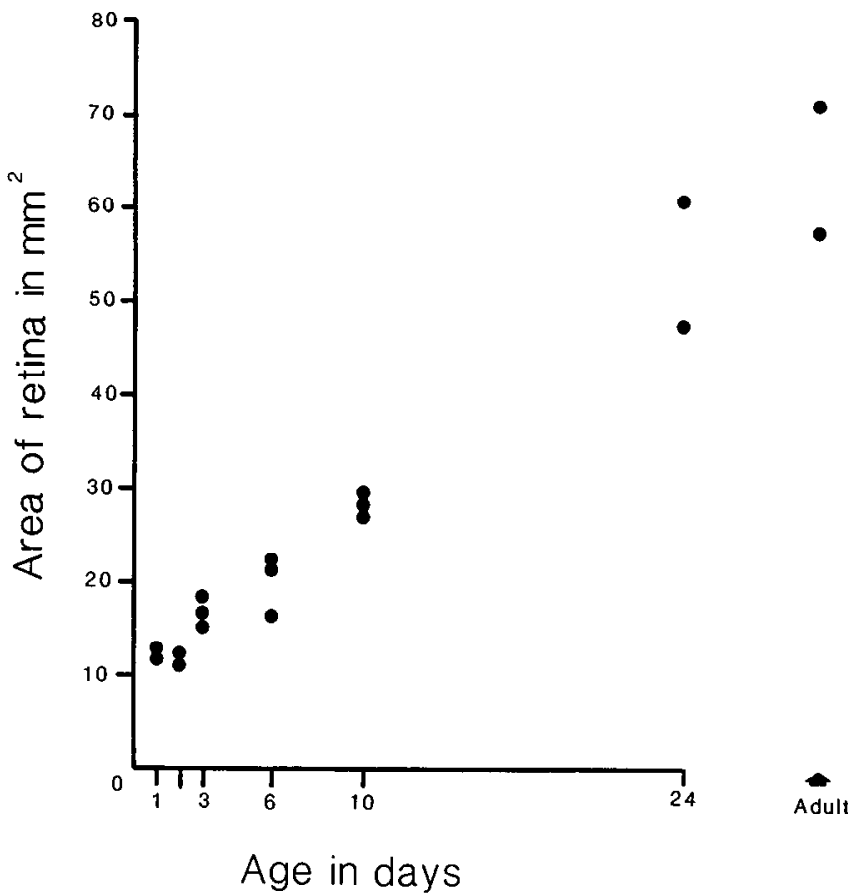

Figure 8. Changes in the area of the retina with age.

alent in other species as well (see Perry, 1982, for review, and Wong and Hughes, 1987a, b). Perry et al. (1983) hypothesized that in the rat, large numbers of displaced amacrine cells migrate into the ganglion cell layer soon after birth. This process may start to take place just before birth in the ferret, since up to a few days before birth only pale-staining cells are seen in the retinal ganglion layer (Greiner and Weidmen, 1981). The continued invasion of the retinal ganglion cell layer by displaced amacrines after birth in the ferret is suggested by the continual rise in the numbers of nonganglion cells after P6.

\section{Dissociability of cell generation, cell death, and retinal growth}

Since cell migration into the ganglion cell layer, retinal ganglion cell death, and retinal growth partially overlap in time, dissociation of their respective contributions to retinal ganglion cell topography is a difficult problem that no single method can resolve. Further complicating the analysis is that many processes of retinal development show spatial gradients (Rapaport and Stone, 1982-1984). For example, cell migration may have ceased centrally while cell death there is in progress, while migration into the periphery might still be in progress and cell death not begun. An observed "uniform" density of cells at this point would therefore have limited significance for the understanding of the actual complement of cells initially forming the ganglion cell layer. A second complication is that over the whole postnatal period, cell death in the retinal ganglion cell layer may occur to an appreciable extent among displaced amacrinc cells, and it is possible that preferential cell loss among ganglion cells in the periphery could be masked by preferential death of displaced amacrine cells in the central region. No single method removes these difficulties: ${ }^{3} \mathrm{H}$-thymidine labeling identifies a unique set of cells, but cannot eliminate the problem of co-occurrence of cell migration and death, and it typically labels a set of cells of mixed type (Sengelaub et al., 1986). Immunohistochemical labeling of displaced amacrine cell types, or HRP labeling of 


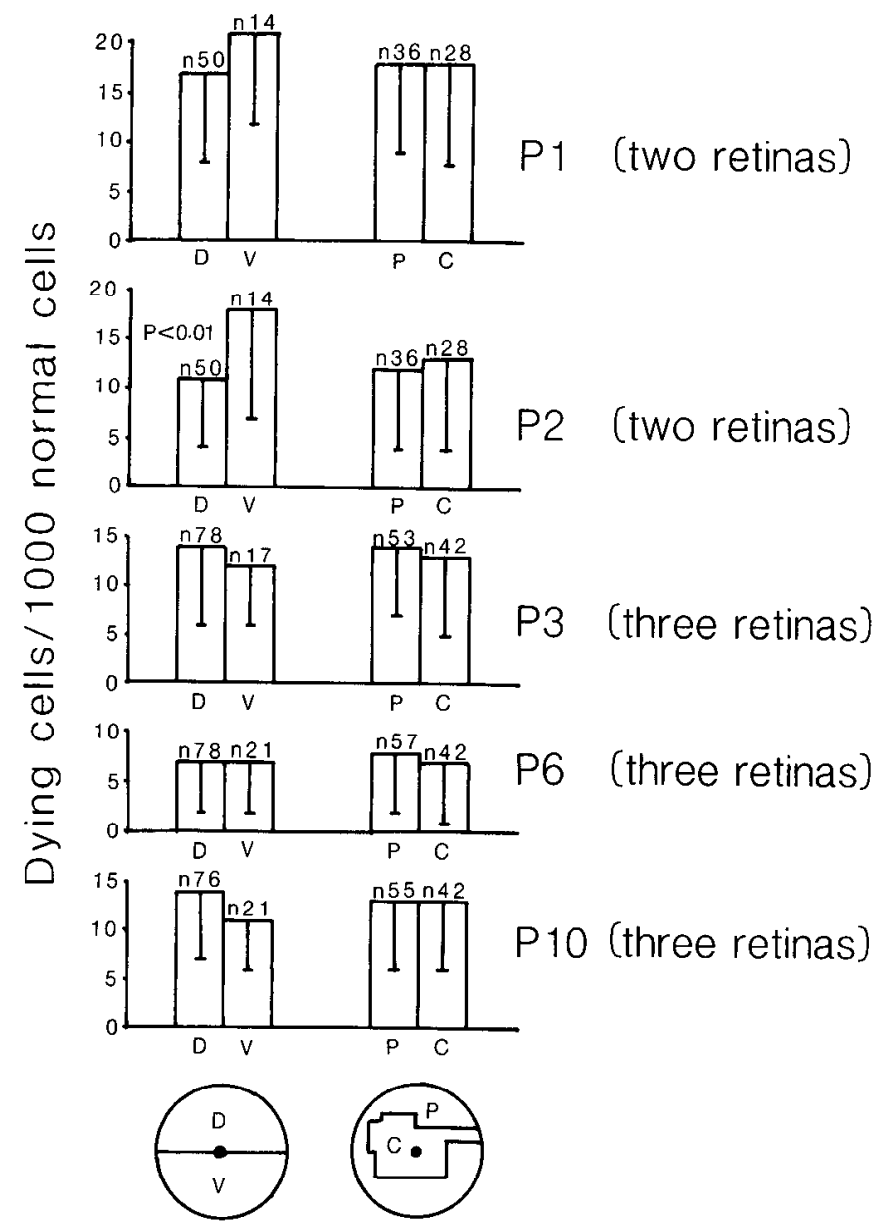

Figure 9. Changes with age in the average incidence of cell death in: dorsal $(D)$ versus ventral $(V)$ retina, and peripheral $(P)$ versus central $(C)$ retina. The dorsal and ventral divisions of the retina were defined by a horizontal line going through the optic disc. The peripheral and central parts of the retina were bounded by an arbitrary line that, in adult (Fig. 7), divides the region containing cells over 3200 ganglion cells $/ \mathrm{mm}^{2}, n$, Total number of retinal sectors averaged to produce each bin.

ganglion cells in conjunction with ${ }^{3} \mathrm{H}$-thymidine labeling further confounds the problem of tracing identified cells because of maturational gradients in the expression of antigens or axons.

Nevertheless, the problem of dissociating these mechanisms is not wholly intractable, in that converging methods may be employed that are at least subject to different sets of confounds or artifacts, and in that some factors are to some degree temporally dissociable, particularly late-occurring retinal growth. In addition, the direction and probable magnitude of some confounds can be reasonably estimated, as follows:

1. Is there differential cell generation across the retinal surface? At no point in the early development of the ganglion cell layer of the ferret was a greater density of cells seen in the presumptive area centralis. In fact, on P3, at the peak of retinal ganglion cell numbers, cell density was highest in the ventral periphery of the retina. Nevertheless, the relationship of this observation to the actual initially generated complement has 3 confounds: (1) the likelihood of continued retinal ganglion cell migration into the ganglion cell layer in the early postnatal period, (2) cell death, and (3) retinal growth. Continued cell migration into the ganglion cell layer until P6 is suggested by the presence of migrating cells in the inner plexiform layer, particularly in the retinal periphery. By P10, the inner plexiform layer is of adult thickness, and the number of cells in the inner plexiform layer is the adult low frequency. Continued cell migration could cause underestimation of the complement of cells, particularly in the retinal periphery at the peak of cell number, of unknown magnitude. Cell death shows substantial spatial nonuniformities in early development, but only between dorsal and ventral, not central versus peripheral retina (Fig. 9). It is possible that early prenatal cell death, confined to the presumptive area centralis (e.g., Provis, 1987), could eliminate an excess density of cells there, rendering the distribution apparently uniform by birth. A conformational change of the prenatal retina could have reduced cell density in the retinal periphery as the retina grew (Mastronade et al., 1984). In sum, analysis of the possible confounds in the assessment of the topography of the originally generated set of retinal ganglion cells would indicate that the initial pool is at least uniform in density, or, more likely, elevated in density in the retinal periphery. Late cell migration to the periphery and early differential growth of the periphery cause its actual cell complement to be systematically underestimated.

2. Does differential cell death produce an area centralis? We found no evidence for a higher incidence of pyknotic cells in the retinal periphery by any reasonable metric. We do not claim that differential cell death may not contribute in part to the development of an area centralis: we have not examined prenatal cell death, and differential death confined to a particular cell class (as in Sengelaub et al., 1986) probably would not be detected by these methods. However, the maximal contribution of cell death can be very roughly delimited. By the time of stabilization of retinal ganglion cell numbers (conservatively, by $\mathrm{P} 10$, allowing for some delayed migration into the ganglion layer), the adult area centralis had not developed: $20 \%$ of the adult center/periphery difference was in evidence, if the initial population is taken to be uniform. This percentage of change in center/periphery disparity potentially attributable to cell death is only a rough estimate, because the initially generated population may not be uniform in density: it may be elevated peripherally, as argued above.

Pyknotic cells have potential, if not demonstrated, problems in their equivalence of clearance times in different retinal areas and different ages (see Provis, 1987), so that nonuniform spatial and changing temporal distributions of pyknotic cells must be interpreted with caution. However, changes in absolute number and relative local densities of retinal ganglion cells confirm that cell death is of large magnitude and of the time course indicated by the pyknotic cells. We thus vicw it as likely that differential cell loss alters gross retinal cell topography, though not by straightforwardly reducing cell density in the periphery. In a prior study in the hamster, it was found that the amount and spatial distribution of cell death appeared to relate to the retinal ganglion subtype (Sengelaub et al., 1986), which has a particular retinal topography that might be a profitable focus for further exploration.

3. Does differential retinal growth produce area centralis? From P10 on, differential retinal growth is the only plausible mechanism that can account for the changing topography of the ganglion cell population. Cell number is stable, as is cell density in the central retina; the retina continues to grow, and cell density is selectively reduced peripherally. Prior to P10, it is probable that differential retinal growth accounts for some of the changes in cell density observed, but the amount cannot be dissociated 
from the contributions of cell death and continued cell migration with this data alone.

\section{Mechanisms of retinal growth}

The effects of retinal growth on the retinal ganglion cell distribution may be described as a relatively symmetric peripheral expansion of the retinal ganglion cell distribution observed on P6-P10 (as suggested for rabbit: Robinson ct al., 1986; and cat: Lia et al., 1987). All the changes in the ganglion cell distribution from P6 to adulthood in the ferret could be caused by greater growth of the retina in the periphery. At P6 there is a dorsalto-ventral gradient in the distribution of retinal ganglion cells that may be construed as the top half of a visual streak. The superimposition of a proportionately greater growth of the peripheral retina on the type of dorsal-to-ventral cell density gradient seen in the P3-6 retina would account also for the lack of symmetry in ganglion cell distribution between the dorsal and ventral retina noted in the adult.

Mastronade et al. (1984) have noted that, during development, the cat's retina occupies a continually decreasing percentage of the sphere of the eye, a process they term "flattening." This also occurs in the ferret, since, according to our measurements, the retina occupies 0.8 of the surface of a sphere at P3, 0.7 at $\mathrm{P} 6-24$, and 0.5 at adulthood. The consequence of retinal flattening is that the peripheral edge of the retina, originally a small section of the retinal sphere, must be dilated to cope with a proportionately larger retinal circumference. This conformational change alone may be sufficient to produce a large amount of the differential ganglion cell density, even when coupled with a uniform spherical expansion. An interesting observation has bccn made by Wilkinson (1986) in the gerbil, a rodent with a prominent visual streak at maturity. In this animal the area of the sphere of the eye not occupied by the retina is oval early in development; in animals that have an area centralis at maturity, the same area is more circular. An asymmetric retinal shape, coupled with symmetric radial expansion and the conformational change described above, could thus result in a visual streak, while a symmetric retinal shape with symmetric expansion and the same conformation change could produce an area centralis.

A second, geometrically distinguishable type of retinal expansion may also contribute to adult topography. This is the differential stretch of retinal surfaces, without a conformational change of the entire retina, in the manner of expansion of a spherical balloon with areas of different thickness (Sengelaub et al., 1986; Robinson, 1987). The 2 mechanisms, differential stretch and retinal flattening, could interact. Thus, differential elasticity of the peripheral retina could permit the conformational change of "flattening."

\section{Speculation on the developmental mechanisms responsible for evolutionary variability in retinal topography}

Developmental changes in the topography of ganglion cells have now been described in a number of species, using methodologies similar to those of this study and subject to the same quantitative qualifications. The species that have been studied are rat (Perry et al., 1983), hamster (Sengelaub et al., 1986), gerbil (Wikler et al., 1986), rabbit (Stone et al., 1985), cat (Stone et al., 1982; Lia et al., 1987) quokka (Beazley and Dunlop, 1983), and human (Provis et al., 1985a). Although this group does not represent an optimal set of species from which to draw rigorous conclusions about developmental mechanisms producing species vari- ability, a few generalizations can be made that may at least help guide the future choice of species. For instance, in all of these studies, the initial distribution of retinal ganglion cells was found to be close to uniform; the largest deviation from uniformity was observed in the rabbit, where the initial visual streak shows a center/periphery difference of about $3 / 1$, small in comparison to the eventual $60 / 1$ disparity seen in adulthood. Cell death appcarcd to show a variable contribution to the development of ganglion cell topography: in the hamster, differential cell loss from periphery accounts for about half of the center-to-periphery disparity in the distribution of the first generated cells (Sengelaub et al., 1986), although it should be noted that the absolute magnitude of this loss is small (the entire center/periphery difference in hamster is $1.5 / 1$ ); losses of this absolute magnitude in other animals with larger center/periphery disparities might well be entirely overlooked. In the human retina, there is a major center-to-periphery difference in the incidence of pyknotic cells (Provis, 1987), but the significance of this observation for the absolute number of cells lost is not known. In neither the cat, rabbit, nor ferret has any contribution of differential cell death been demonstrated; neither, however, has it been entirely excluded.

In all of the above cases, differential retinal growth has either been directly implicated as a mechanism or as a logical necessity of the timing of early morphogenetic effects. Unlike differential generation or death, the range of demonstrated interspecific variability in ganglion cell distribution produced by differential growth is extreme, from a 1.25 disparity in the hamster, to a $20 / 40$ disparity in the cat and rabbit. Comparing ferrets and cats, the timing and duration of major landmarks in retinal development, such as peak ganglion cell numbers, onset of neuronal growth and differentiation, and the appearance of a reasonably adultlike ganglion cell topography, are roughly equivalent. However, the eye size reached by the cat in this period is 6 times larger. It is interesting to speculate that the difference in retinal topography in these 2 species is entirely due to greater differential stretch of the retina in the cat; given a similar set of initial conditions producing differential retinal stretch in the 2 animals, simply allowing the cat's eye size to expand at a greater rate may produce a more specialized area centralis. A similar conclusion has been reached in the comparison of 2 other closely related animals, the hamster and the gerbil (Sengelaub et al., 1986; Wikler et al., 1986). Clearly, however, large eye size alone does not inevitably produce an area centralis (Hughes, 1977): retinal organization predisposing to differential stretch must also exist.

A particular cpigenetic event may be required to produce the differential elasticity or growth of the peripheral retina. Candidates might be small gradients in early neurogenesis, or cell death, or early gradients of maturation, or development of connectivity in the retina (Maslim and Stone, 1986). Future studies are required to determine the interaction of initial retinal conformation, pattern of maturation, and rate and amount of retinal growth to determine the relationship of retinal phylogeny to its ontogeny.

\section{Appendix}

\section{Obliquity correction}

The correction for obliquity (see Fig. 10) was derived by the Pythagorean theorem from the inner (R1) and outer (R2) radii of the ganglion cell layer, and from the dorsal-ventral section level $(H)$ in the following manner: 


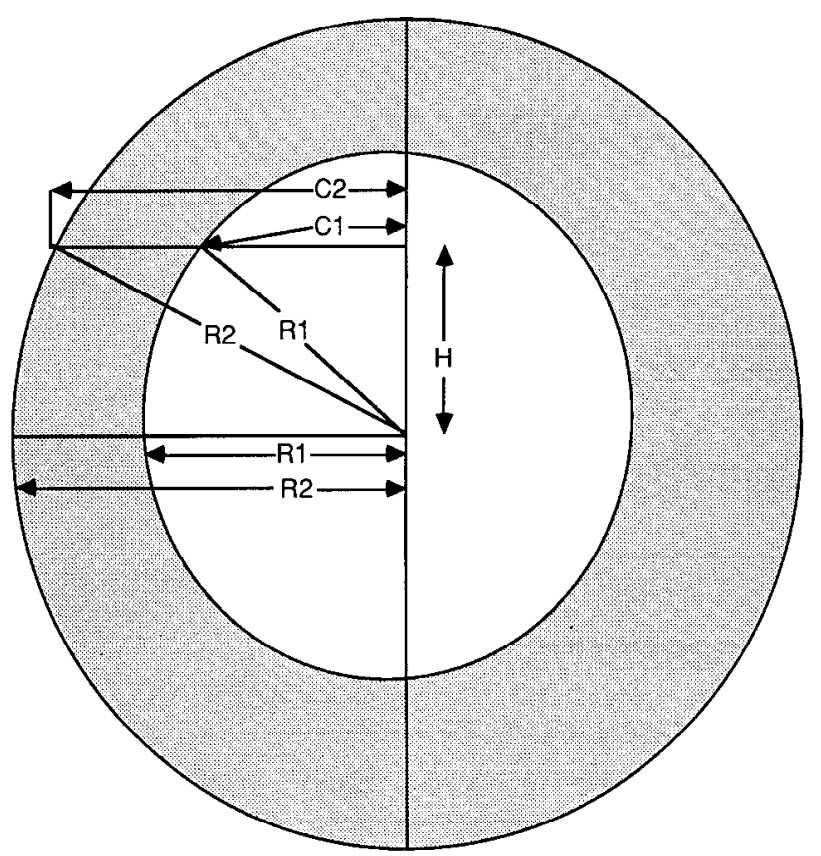

Figure 10. Schematic of the effect of oblique retinal sections on apparent retinal thickness. The retina is represented as a sectioned sphere with an absolute thickness of R2 (outer diameter) - R 1 (inner diameter). At any section level $\mathrm{H}$, the apparent retinal thickness $(\mathrm{C} 2-\mathrm{C} 1)$ may be corrected to the thickness of a perpendicular section using the formula described in the text.

1. If the retinal thickness of a normal section of the retina is the difference between the inner and outer retinal radii (R2 $\mathrm{R} 1$ ), and the thickness of an oblique section is $\mathrm{C} 2-\mathrm{C} 1$, then

$$
\begin{aligned}
& \mathrm{Cl}=\sqrt{(\mathrm{R} 1)^{2}-(\mathrm{H})^{2}} \\
& \mathrm{C} 2=\sqrt{(\mathrm{R} 2)^{2}-(\mathrm{H})^{2}}
\end{aligned}
$$

2. The obliquity correction used was the ratio of the thickness of an oblique section to that of a normal section, (C2-C1)/ (R2 - R1), expressed by substitution:

$$
\left[\sqrt{(\mathrm{R} 2)^{2}-(\mathrm{H})^{2}}-\sqrt{(\mathrm{R} 1)^{2}-(\mathrm{H})^{2}}\right] /(\mathrm{R} 2-\mathrm{R} 1) .
$$

Thus the apparent increase in section thickness can be corrected for at any retinal height.

\section{Retinal area computation}

1. If the eye is approximately defined by a sphere of radius $r$, then $r$ is $10 \mu \mathrm{m} \times$ number of sections through the eye/2. If the area of each strip of eye is $A, t$ and $t^{\prime}$ are known section levels, and $a$ and $a^{\prime}$ the areas of eye above the lower and upper borders of the strip (Fig. 11) then

$$
\begin{gathered}
A=a-a^{\prime} \\
a=2 \pi r^{2}(1-\cos \phi) \\
a^{\prime}=2 \pi r^{2}\left(1-\cos \phi^{\prime}\right) \\
a-a^{\prime}=2 \pi r^{2}\left(\cos \phi-\cos \phi^{\prime}\right) \\
r-t=r \cos \phi \\
r-t^{\prime}=r \cos \phi^{\prime} \\
A=a-a^{\prime}=2 \pi r\left(t^{\prime}-t\right) .
\end{gathered}
$$

2. The retina seen in each strip might fill a complete circle, a

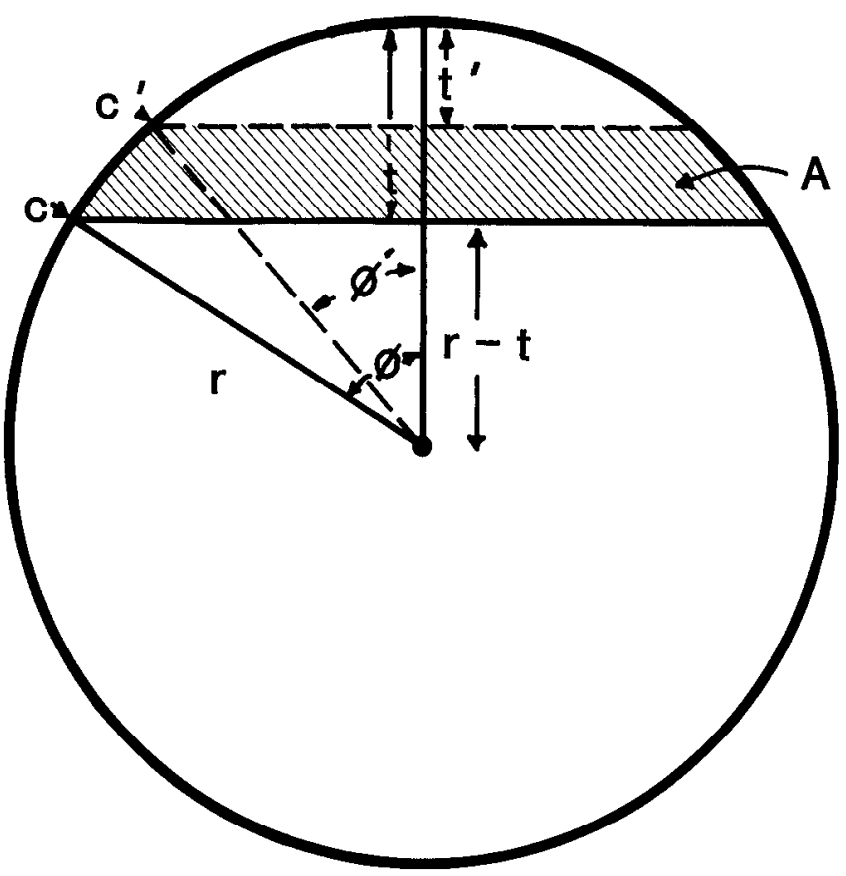

Figure 11. Schematic of the relinal measurements used to determine total retinal area and retinal cell number. $r$, Radius of the eye (number of sections through eye $\times$ section thickness $/ 2$ ); $t$, level of horizontal section forming the ventral boundary of the retinal strip $(A)$ whose area is to be computed; $t^{\prime}$, level of horizontal section forming the dorsal boundary of $A ; c$ and $c^{\prime}$, circumference of the retinal section at $t$ and $t^{\prime}$, respectively.

hemicircle or less. Expected eye circumference $(c)$ at each section height (Fig. 11) was determined and compared to the measured retinal length at that level. The area measurement $(A)$ above the section was reduced proportionately. The circumference $(c)$ of the eye at each section level was calculated thus:

$$
\begin{gathered}
c=2 \pi r \sin \phi \\
c=2 \pi r \sin \cos ^{-1}(r-t / r) .
\end{gathered}
$$

3. The area of the retinal strip above the section thus approximated $A \times$ measured retinal length/computed circumference. To obtain the total area of each retina, the areas of all the strips were summed, and from this, the proportion of the surface area of the eye occupied by retina was obtained.

4. As mentioned previously, the retinal strips had been further subdivided into 2-5 sectors within which cell density was determined to be relatively uniform (as can be seen in Figs. 5 and 6). To obtain total ganglion cell number, mean cell number per sector was multiplied by the area of each retinal sector, and those cell numbers summed over the entire retinal area to determine total cell number. Cell numbers computed by this method for adult retinas were comparable to those determined from wholemounts and optic nerve axon counts (see Fig. 7; also Hendcrson, 1985).

\section{References}

Abercrombie, M. (1946) Estimation of nuclear populations from microtome sections. Anat. Rec. 94: 239-247.

Adams, J. C. (1977) Technical considerations on the use of horseradish peroxidase as a neuronal marker. Neuroscience 2: 239-247.

Beazley, L. D., and S. A. Dunlop (1983) The evolution of an area centralis and visual streak in the marsupial Setonix brachyurus. $\mathbf{J}$. Comp. Neurol. 216: 211-231. 
Chalupa, L. M., R. W. Williams, and Z. Henderson (1984) Binocular interaction in the fetal cat regulates the size of the ganglion cell population. Neuroscience 12: 1139-1146.

Crespo, D., D. D. M. O'Leary, and W. M. Cowan (1985) Changes in the numbers of optic nerve fibres during late prenatal and postnatal development in the albino rat. Dev. Brain Res. 19: 129-134.

Cunningham, T. J., I. M. Mohler, and D. L. Giordano (1982) Naturally occurring neuron death in the ganglion cell layer of the neonatal rat: Morphology and evidence for regional correspondence with neuron death in superior colliculus. Dev. Brain Res. 2: 203-215.

Greiner, J. V., and T. A. Weidman (1981) Histogenesis of the ferret retina. Exp. Eye Res. 33: 315-322.

Henderson, Z. (1985) Distribution of ganglion cells in the retina of adult pigmented ferret. Brain Res. 358: 221-228.

Henderson, Z., K. C. Wikler, and B. L. Finlay (1985) Developmenta changes in cell death and retinal ganglion cell distribution in the postnatal ferret retina. Soc. Neurosci. Abstr. 11: 15.

Horsburgh, G. M., and A. J. Sefton (1985) The distribution and clearance of degenerating retinal ganglion cells in the neonatal rat. Proc. Aust. Physiol. Pharmacol. Soc. 16: 45 .

Hughes, A. (1975) A quantitative analysis of the cat retinal ganglion cell topography. J. Comp. Neurol. 163: 107-138.

Hughes, A. (1977) The topography of vision in mammals of contrasting life style: Comparative optics and retinal organization. In Handbook of Sensory Physiology, vol. 7, pt. 5, F. Crescitelli, ed., pp. 613756, Springer-Verlag, Berlin.

Illing, R. B., and H. Wässle (1981) The retinal projection to the thalamus in the cat: A quantitative investigation and a comparison with the retinotectal pathway. J. Comp. Neurol. 202: 265-285.

Lam, K., A. J. Sefton, and M. R. Bennett (1982) Loss of axons from the optic nerve of the rat during early postnatal development. Dev. Brain Res. 3: 487-491.

Lia, B., R. W. Williams, and L. M. Chalupa (1987) Non-uniform growth of the fetal retina can account for the prenatal development of regional specialization in the ganglion cell layer of the cat. Science 236: 848-851.

Linden, D. C., R. W. Guillery, and J. Cucchiarro (1981) The dorsal lateral geniculate nucleus of the normal ferret and its postnatal development. J. Comp. Neurol. 203: 189-211.

Maslim, J., and J. Stone (1986) Synaptogenesis in the retina of the cat. Brain Res. 373: 35-48.

Masronade, D. M., M. A. Thibeault, and Dubin, M. W. (1984) Nonuniform postnatal growth of the cat retina. J. Comp. Neurol. 288: 598-608.

$\mathrm{Ng}$, A. Y. K., and J.Stone (1982) The optic nerve of the cat: appearance and loss of axons during normal development. Dev. Brain Res. 5: 263-271.

Perry, V. H. (1981) Evidence for an amacrine cell system in the ganglion cell layer of the rat retina. Neuroscience 6: 931-944.

Perry, V. H. (1982) The ganglion cell layer of the mammalian retina In Progress in Retinal Research, N. Osborne and G. Chader, eds., pp. 53-80, Pergamon, Oxford.

Perry, V. H., and M. Walker (1980) Morphology of cells in the ganglion cell layer during development of the rat retina. Proc. R. Soc. Lond. (Biol.) 208: 433-445.

Perry, V. H., Z. Henderson, and R. Linden (1983) Postnatal changes in retinal ganglion cell and optic axon populations in the pigmented rat. J. Comp. Neurol. 219: 356-368.

Potts, R. A., B. Dreher, and M. R. Bennett (1982) The loss of ganglion cells in the developing retina of the rat. Dev. Brain Res. 3: 481-486.

Provis, J. M. (1987) Patterns of cell death in the ganglion cell layer of the human fetal retina. J. Comp. Neurol. 259: 237-246.

Provis, J. M., D. van Driel, F. A. Billson, and P. Russell (1985a) Development of the human retina: Patterns of cell distribution and redistribution in the ganglion cell layer. J. Comp. Neurol. 233: 429452.
Provis, J. M., D. van Driel, F. A. Billson, and P. Russell (1985b) IIuman fetal optic nerve: Overproduction and climination of retinal axons during development. J. Comp. Neurol. 238: 92-100.

Rakic, P., and K. P. Riley (1983) Overproduction and elimination of retinal axons in the fetal rhesus monkey. Science 219: 1441-1444.

Rapaport, D. H., and J. Stone (1982) The site of commencement of maturation in mammalian retina: Observations in the cat. Dev. Brain Res. 5: 273-279.

Rapaport, D. H., and J. Stone (1983) Time course of morphological differentiation of cat retinal ganglion cells: Influence on soma size. $J$ Comp. Neurol. 221: 42-52.

Rapaport, D. H., and J. Stone (1984) The area centralis of the retina in the cat and other mammals: Focal point for function and development of the visual system. Neuroscience 11: 289-301.

Robinson, S. R. (1987) Ontogeny of the area centralis in the cat. J. Comp. Neurol. 254: 50-71.

Robinson, S. R., B. Dreher, G. M. Horsburgh, and M. J. McCall (1986) Development of the ganglion cell density gradient in the rabbit. Soc. Neurosci. Abstr. 12: 985.

Sengelaub, D. R., and B. L. Finlay (1982) Cell death in the mammalian visual system during normal development: I. Retinal ganglion cells. J. Comp. Neurol, 204: 311-317.

Sengelaub, D. R., R. P. Dolan, and B. L. Finlay (1986) Cell generation, death and retinal growth in the development of the hamster retinal ganglion cell layer. J. Comp. Neurol. 246: 527-543.

Stone, J. (1965) A quantitative analysis of the distribution of ganglion cells in the cat's retina. J. Comp. Neurol. 124:337-352.

Stone, J. (1978) The number and distribution of ganglion cells in the cat's retina. J. Comp. Neurol. 180: 753-772.

Stone, J. (1983) Parallel Processing in the Visual System, pp. 265325, Plenum, New York.

Stone, J., and D. H. Rapaport (1986) The role of cell death in shaping the ganglion cell layer population of the adult cat retina. In Visual Neuroscience, J. D. Pettigrew, K. J. Sanderson, and W. R. Levick, eds., pp. 157-165, Cambridge U. P., Cambridge, UK.

Stone, J., D. H. Rapaport, R. W. Williams, and L. Chalupa (1982) Uniformity of cell distribution in the ganglion cell layer of prenatal cat retina: Implications for mechanisms of retinal development. Dev. Brain Res. 2: 231-242.

Stone, J., M. Egan, and D. H. Rapaport (1985) The site of commencement of retinal maturation in the rabbit. Vis. Res. 25:309. 317.

Tucker, G. S. (1978) Light microscopic analysis of the kitten retina: Postnatal development in the area centralis. J. Comp. Neurol. 180. 489-500.

Vitek, D. J., J. D. Schall, and A. G. Leventhal (1985) Morphology, central projections, and dendritic field orientation of retinal ganglion cells in the ferret. J. Comp. Neurol. 241: 1-11.

Wikler, K. C., M. Hatlee, and B. L. Finlay (1986) Developmental mechanisms for the evolution of species differences in retinal number and distribution. Soc. Neurosci. Abstr. 12: 120.

Wilkinson, F. (1986) Eye and brain growth in the mongolian gerbil (Meriones unguiculatus) Behav. Brain Res. (in press).

Williams, R. W., M. J. Bastiani, B. Lia, and L. M. Chalupa (1986) Growth cones, dying axons and developmental fluctuations in the fiber population of the cat's optic nerve. J. Comp. Neurol. 246: 3269.

Wong, R. O. L., and A. Hughes (1987a) The morphology, number and distribution of a large population of confirmed displaced amacrine cells in the adult cat retina. J. Comp. Neurol. 255: 159-177.

Wong, R. O. L., and A. Hughes (1987b) Developing neuronal populations of the cat retinal ganglion cell layer. J. Comp. Neurol. 262: 473-495.

Wong, R. O. L., and A. Hughes (1987c) Role of cell death in the topogenesis of neuronal distributions in the developing cat retinal ganglion cell layer. J. Comp. Neurol. 262: 496-511. 